\title{
Multimedia Technology Supporting Manufacturing Education
}

\author{
Henry W. Kraebber, P. E. \\ Purdue University - School of Technology
}

Accredited programs in manufacturing engineering technology stress hands on applications and problem solving using the computer as a tool. The computers found in technology laboratories come in many different forms directed at solving a particular problem, developing and documenting a product design, controlling a process or machine, or even helping to manage the business side of the operation. Students learn to program and operate many different computer based applications. The computer is rarely used in manufacturing classes as a teaching tool or as an aid to the instructor, other than in the basic applications of word processing and spreadsheet programs. The powerful computers in manufacturing labs are not often used to improve the teaching or learning activities of manufacturing technology classes.

The continuing increases in computing power and the lowering of the costs associated with the new technology are helping to create effective new applications that can help manufacturing educators be better teachers. This paper looks at recent literature on the application of interactive multimedia (IMM) technology as a teaching tool and considers some of the expected benefits and the probable "pitfalls" which may be encountered. Manufacturing educators are encouraged to carefully plan to use IMM systems as an aid to teaching their classes.

The explosive growth in the capabilities of personal computers has helped bring the computer into nearly every facet of the operation of a business. Manufacturing educators have used computers as tools to solve industrial problems for years. Computer instruction on programming and the use of software packages is a major element of accredited programs in manufacturing engineering technology. Manufacturing laboratories at a two year or four year institution use computers for engineering design, manufacturing planning and control, calculations and productivity analysis, quality control, cost analysis and reporting. The manufacturing lab is designed to represent the systems and processes students will find in industry.

The rapid growth of computer capability also provides opportunity for computers to become an active part of the process of teaching and learning. The use of computers as teaching tools is not new, but use has often been limited to word processing and spreadsheet calculations. Interactive multimedia (IMM) can be the medium that unlocks the power of the computer as a tool for manufacturing education. 
Research by Chang, McCuen and Sircar (1995) considers the strengths and weaknesses of multimedia. This team of authors has identified several major advantage categories. The development of IMM allows the teacher to be the author and control the format of the instruction. The instruction can be self paced by the student, and with appropriate software and hardware can be accessible at any time and place. IMM provides the capability for active learning and student interaction with the system. The authors expect retention to be better than with traditional methods of instruction because students can observe real world phenomena through motion or still pictures. Computers are a part of much of our lives today. The computer based nature of IMM is a natural application of computer technology that is gaining acceptance by people.

There are problems, however. Chang, McCuen and Sircar go on to state that the biggest problem holding back the use of IMM is the development and production time investment required by the teacher. Woolf and Hall (1995) confirm the problem of costs for resources to plan contents, develop graphics, do the programming, and assure the systems fit well with the learner. Both groups of authors report the costs of hardware and software are becoming less of a concern as the technology advances. In spite of any problems, the computer is not going to go away. Instructors must take on the challenge of making the computer into a tool that really helps us teach more effectively. All of the reference sources found to support this paper give encouragement and suggestions on the use of IMM.

IMM offers the opportunity for exciting new additions to our courses as demonstrated in the examples given in the articles such as interactive simulations, case studies and scenarios. Ranky (1996) provides an excellent discussion of interactive multimedia applications for manufacturing and product design education. CD ROM based software packages are now available on manufacturing a growing number of topics. These disks provide the user with programs which integrate text, graphics and video clips with sound. Ranky's work includes programs related to robotics, servo positioning systems and flexible manufacturing systems. This type of technology can help bring concepts to life in ways that traditional methods can not.

Using the computer as a teaching tool seems like a great idea. Students are depending on technology educators to bring computer-aided instruction into their classrooms. However going beyond using the computer as just a word processor or spreadsheet tool will require instructors to sharpen their skills as educators and develop the required new set of IMM skills. There is a great temptation to rush out and start playing with the new software in an effort to jump on the IMM bandwagon.

A common thread through all the articles is the need for careful planning before rushing into an implementation of IMM because of the high development costs. Educators can draw from a variety of reference sources and the experience of others using IMM successfully. The use of IMM as a teaching tool places emphasis on the need for planning at the start of the project. First time IMM system developers should take time to review the work done by others before starting to implement new IMM systems. The Multimedia in Manufacturing Education (MiME) project at Georgia Tech discussed by Thompson, Hodges, Daley and Rogers (1995) is a good example of the type of resource support and sample models that can help educators develop effective IMM applications. 
The development of effective IMM systems requires educators to consider the fundamental elements of educational design. McCuen and Chang (1995) emphasize the need for evaluation of the IMM program "from the time it is conceived, through the time when the program is being implemented, and after the program ends." The developer's strategy for evaluation of the IMM should be part of the educational plan. The emphasis of the educational plan should be on the development of goals, the identification of the desired learning outcomes, the development of strategies, activities, instruments and techniques which will help the learner achieve the objectives, and the implementation of the plans and development of the specific elements of the IMM system. Evaluation of the system throughout the development and implementation process can help assure effective results.

Documented plans and models of IMM systems are available for educators to review. The article by Woolf and Hall does a good job presenting the critical elements of an active learning environment which supports IMM. These active elements include a clearly defined model with knowledge of the components in the environment, system parameters which the user can change and control, and immediate response of the system to user inputs. They also provide case descriptions and examples of several multimedia techniques including simulations, tutoring systems, explanatory systems and interactive collaborations. Funding for the work on the development of tools and the development of applications of the new IMM technology has come through Technology Reinvestment Projects sponsored by the Department of Defense. High level program support should lead to the development of improved systems and models that will help educators with future development projects.

The message is clear. IMM is an exciting tool that can help manufacturing education classes now. There is no reason to be afraid of the new technology and few reasons to wait. A successful IMM application can be the result of a well planned educational design. Time will be required to learn to use the tools of IMM, but it is time that must be spent. The developer must carefully plan the instruction and the use of the new technology. The book by Newby, Stepich, Lehman and Russell can provide manufacturing educators without a rich background in teaching with an important perspective on the use of media and computers, the need for clear objectives, the fundamentals of educational design and evaluation techniques. The use of computers and interactive multimedia in the class room can help bring manufacturing classes to a new level of effectiveness. However, the increased use of the computer and multimedia in the class will bring the educational plan under the microscope! Good plans will become even better, and poor designs will become disasters...

Creative solutions will emerge which will allow the needed development effort and time to be applied to IMM projects. Class projects may be developed to bring the student into the development effort. Assignment of a term report which requires a multimedia component can provide students with a challenging new view of the material. Networks of manufacturing educators can be formed which will help faculty keep out of the trap of reinventing the wheel with respect to interactive programs.

First time IMM users do not have to go it alone. There are a growing number of support resources available to help instructors be successful with IMM implementations. Organizations 
such as ASEE, SME and the CIM in Higher Education Alliance provide opportunities for manufacturing educators to learn from each other about multimedia and the best ways to utilize it. More and more instructors at all levels are starting to give IMM a try in some form. It is time to bring the exciting world of IMM into manufacturing classes. The key is planning! Educators still need to understand the fundamentals of learning and instructional design that lead to effective courses.

\section{References}

Chang, P. C., McCuen, R. H., Sircar, J. K. (1995). "Multimedia-based instruction in engineering: Strategy." Journal of Professional Issues in Engineering Education and Practice. 121(4). 216-219.

Newby, T. J., Stepich, D. A., Lehman, J. D. \& Russell, J. D. Instructional technology for teaching and learning. Englewood Cliffs, NJ.: Merrill/Prentice Hall. (1996).

McCuen, R. H., Chang, P. C. (1995). "Multimedia-based instruction in engineering: Evaluation.” Journal of Professional Issues in Engineering Education and Practice. 121(4). 220-224.

Ranky, P.G. (1996). "Interactive multimedia for educating computer integrated manufacturing and product design". Manufacturing for the $21^{\text {st }}$ Century, Volume III: Preparing World Class Manufacturing Professionals. Dearborn, MI.: Society of Manufacturing Engineers.

Thompson, C., Hodges, L., Daley, W., Rogers, E. (1995). "Multimedia in manufacturing education mime." Proc., Frontiers in Education, 25th Annu. Conf., Atlanta, GA., 927-930.

Woolf, B. P., Hall, W. (1995). "Multimedia pedagogues interactive systems for teaching and learning." Computer. 28(5). 74-80.

HENRY W. KRAEBBER, has fifteen years of experience and leadership in manufacturing operations, engineering, quality and management. He is now an Associate Professor and teaches courses in manufacturing operations, manufacturing quality control and integrated systems which support the degree program in Computer Integrated Manufacturing Technology. BSIE from Purdue University. MS Engr. from Iowa State University. 